\title{
ISB News November 2010: From the President
}

\author{
Paul J. Beggs
}

(C) ISB 2010

While the focus of ISB News is often on the news and accomplishments of the Society, it is also an ideal forum in which to acknowledge and celebrate the accomplishments, when particularly special, of individual members of the Society. At the beginning of September we received such news - that Prof. Mark D. Schwartz, the ISB Secretary, had just been named a University of Wisconsin-Milwaukee (UWM) Distinguished Professor by the UW Board of Regents.

Distinguished Professor is the UW System's most prestigious title. It recognises a continuous record of scholarly accomplishments, significant contribution to an academic field, and strengthened research efforts and opportunities. Appointment requires the positive recommendation of the UWM Committee of Distinguished Professors.

Mark is, of course, a climatologist and expert in the field of phenology, and has developed models based on the first leafing and blooming of lilacs and honeysuckles over the last 50 years that show a correlation between temperatures and spring plant growth. His models, however, also highlight relationships among plant development, water vapour, and carbon dioxide levels in the atmosphere at different times of the year. His research also includes applications of air mass analysis and assessing vegetation condition with remote sensing imagery.

In 2005, Mark was awarded the Ronald F. Abler Distinguished Service Honors by the National Council of

\section{P. J. Beggs $(\square)$}

Environmental Science, Department of Environment

and Geography, Macquarie University,

Sydney, Australia

e-mail: paul.beggs@mq.edu.au the Association of American Geographers (AAG). His models that simulate spring first leaf and first bloom were 1 of 24 cited recently in the US Environmental Protection Agency's 2010 report on climate change indicators. He has been quoted in a wide variety of news media, including USA Today, the Milwaukee Journal Sentinel and the Minneapolis Star-Tribune.

Mark's most highly cited peer-reviewed journal paper, at 103 Times Cited (Thomson Reuters 2010), is the paper he co-authored with Bernhard E. Reiter titled "Changes in North American spring", which was published in the International Journal of Climatology in 2000 [20(8):929932]. Another of his many publishing highlights is his 1998 Nature paper. Mark has also been cited by, and reviewed, the Intergovernmental Panel on Climate Change's Working Group II contribution to the Fourth Assessment Report, published in 2007. In addition to Mark's many contributions to the ISB over the years (including, of course, as IJB Field Editor for Phenology), he is currently also Chair of the Association of American Geographers Climate Specialty Group, and Chair of the USA National Phenology Network Board of Directors.

The International Society of Biometeorology is honoured to have scientists of Mark's calibre amongst its membership, serving, amongst other things, as role models and inspiration for those at earlier stages of their careers.

\section{Reference}

Thomson Reuters (2010) ISI Web of Knowledge, Web of Science. http:// thomsonreuters.com/products services/science/science products/a-z/ isi_web_of_knowledge. Accessed 9 September 2010 